\title{
Correction to "Ionospheric electron heating, optical emissions, and striations induced by powerful HF radio waves at high latitudes: Aspect angle dependence"
}

\author{
M. T. Rietveld, M. J. Kosch, N. F. Blagoveshchenskaya, V. A. Kornienko, T. B. Leyser,
} and T. K. Yeoman

Received 4 March 2004; published 21 April 2004.

INDEX TERMS: 2403 Ionosphere: Active experiments; 6929 Radio Science: Ionospheric physics;

7839 Space Plasma Physics: Nonlinear phenomena; 2471 Ionosphere: Plasma waves and instabilities; 6944

Radio Science: Nonlinear phenomena

Citation: Rietveld, M. T., M. J. Kosch, N. F. Blagoveshchenskaya, V. A. Kornienko, T. B. Leyser, and T. K. Yeoman (2004), Correction to "Ionospheric electron heating, optical emissions, and striations induced by powerful HF radio waves at high latitudes: Aspect angle dependence," J. Geophys. Res., 109, A04306, doi:10.1029/2004JA010460.

[1] In the paper "Ionospheric electron heating, optical emissions, and striations induced by powerful $\mathrm{HF}$ radio waves at high latitudes: Aspect angle dependence" by M. T. Rietveld, M. J. Kosch, N. F. Blagoveshchenskaya, V. A. Kornienko, T. B. Leyser, and T. K. Yeoman (Journal of Geophysical Research, 108(A4), 1141, doi:10.1029/ 2002JA009543, 2003), there should have been color versions of Figures 1 and 2 at the end of the online pdf and at the back of the print issue. These figures are reprinted in color here, along with their captions. 


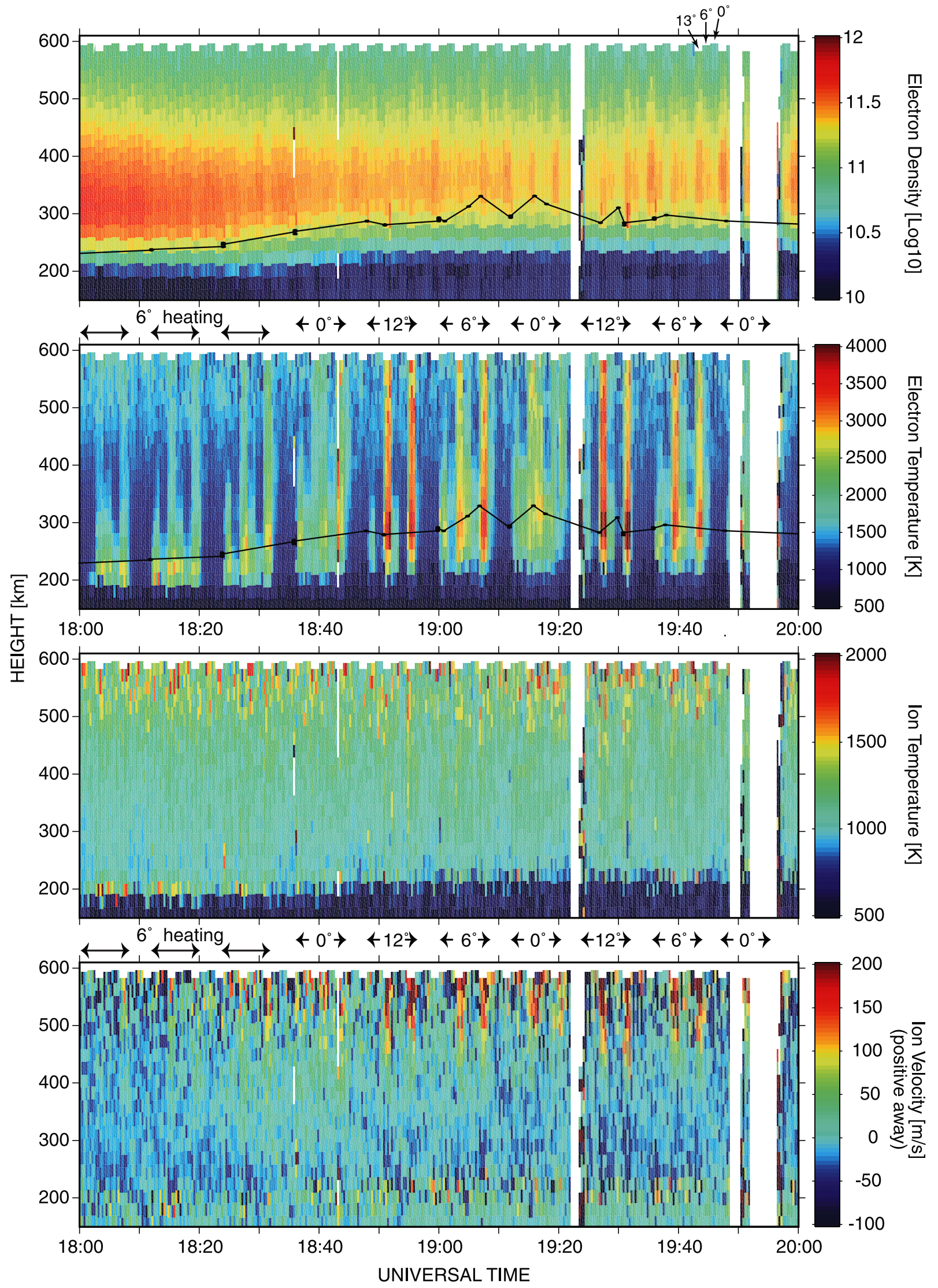

Figure 1 
Figure 1. Data from the EISCAT UHF radar at Tromsø on 7 October 1999, obtained using the long-pulse and analyzed with $20 \mathrm{~s}$ integration time, showing the effects of HF pumping. The HF was cycled 8 min on, 4 min off, with the beam directed at southward zenith angles shown below the upper and above the lowest panels. The UHF antenna was continually scanned in a 4 -min cycle between almost the same positions, $6^{\circ}, 0^{\circ}, 12.8^{\circ}$ zenith angles, which are distinguishable by the varying upper altitude as labeled at the upper right of the first panel. The solid line in the upper two panels connects points indicating the HF-enhanced ion line (HFIL) height obtained from the two power profiles. The HFIL height should be close to but below the HF reflection height. 


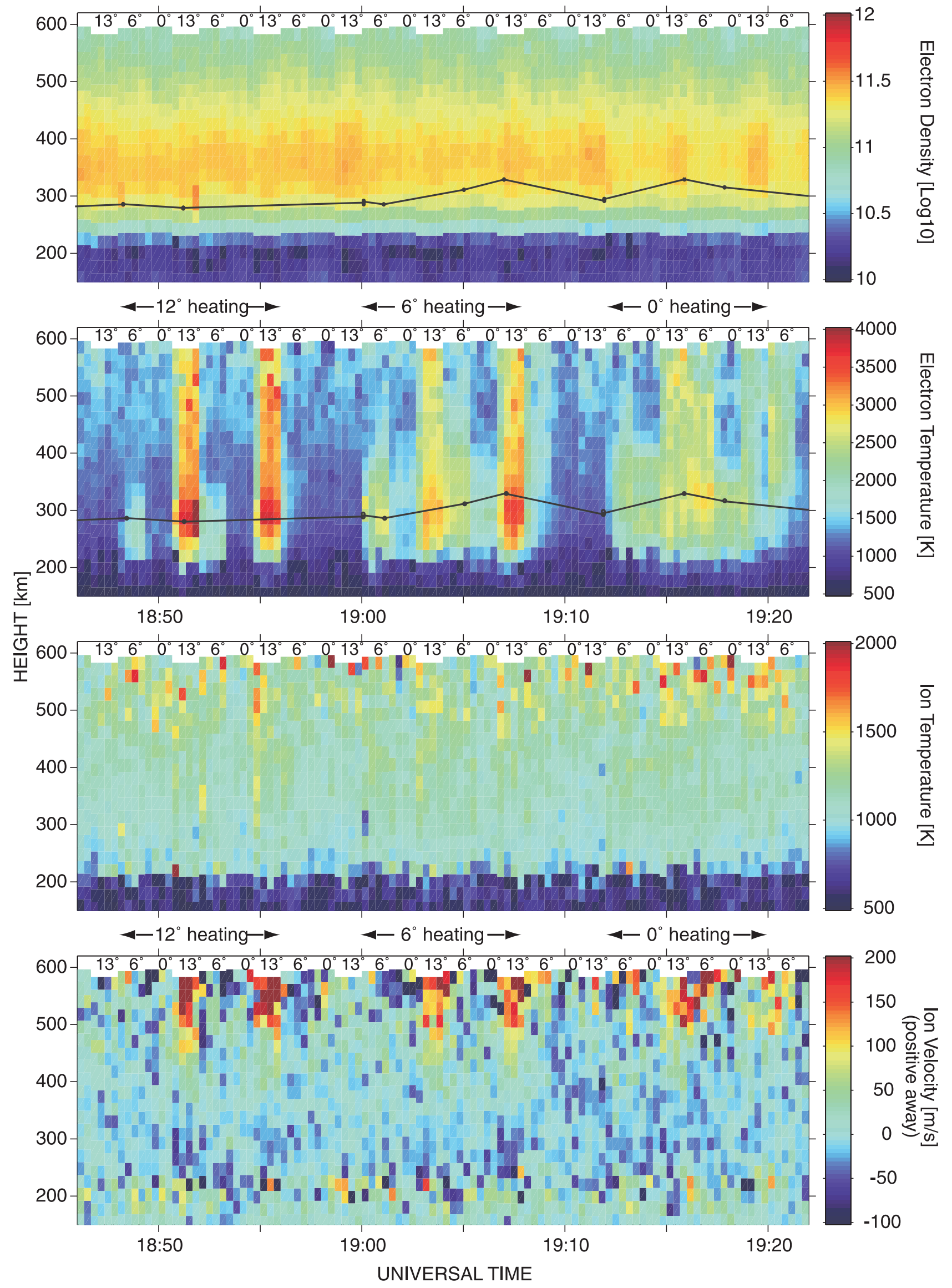

Figure 2 
Figure 2. A subset of the EISCAT UHF data from the 7 October 1999 data in Figure 1, showing more detail. The numbers near the top of each panel show the UHF antenna zenith angles, whereas those between the upper two and lower two panels show the HF beam zenith angles. The height of the HFIL is shown by the dots joined by solid lines in the upper two panels. 